\title{
Withdrawal of allopurinol in patients with gout
}

\author{
W. Y. LOEBL AND J. T. SCOTT \\ From Charing Cross Hospital and Kennedy Institute of Rheumatology, London
}

The xanthine oxidase inhibitor allopurinol effectively lowers the plasma level of uric acid and the drug has become widely used in the treatment of gout, especially in patients with renal failure, uric acid calculi, or intolerance to uricosuric agents (Scott, Hall, and Grahame, 1966). Various theoretical complications of treatment have been considered from time to time, such as possible incorporation of ribonucleotide into genetic material or the effects of crystals of allopurinol in voluntary muscle, as discussed below. For these reasons it was thought reasonable a few years ago to determine the effect of discontinuing allopurinol therapy in gouty patients who were not over-producers of uric acid and whose renal function was not impaired.

\section{Plan of study}

Medication was discontinued in 33 patients with gout (32 men and one woman), with a mean age of 58 years (range 33-75 yrs). In five of them the drug would have had to be discontinued in any case because of a skin rash or malaise probably attributable to the drug; in 28 the drug was stopped in the absence of side effects after full discussion with individual patients. None of these latter patients had impairment of renal function (as estimated by blood urea) and none were over-producers of uric acid as indicated by a 24-hour urinary uric acid excretion of less than $600 \mathrm{mg}$ on a low-purine diet.

The mean length of history of gout before starting treatment had been 15 years (range $0.5-42$ yrs), with an average of 4.5 attacks per year before starting therapy. The mean duration of allopurinol treatment before the drug was discontinued was 93 weeks (range 19-236 wks), and the mean duration off allopurinol at the time this analysis was made was 86 weeks (range 14-210 wks).

\section{Results}

\section{(1) PLASMA URIC ACID}

The mean level of plasma uric acid before starting therapy had been $8.4 \mathrm{mg} / 100 \mathrm{ml}$ (SD 1.1), falling to $5.5 \mathrm{mg} / 100 \mathrm{ml}($ SD 1.2) after allopurinol therapy was established. After the withdrawal of allopurinol, uric acid levels rose to pretreatment figures in all patients (mean $8.8 \mathrm{mg} / 100 \mathrm{ml}$, SD 1.2). This rise in plasma uric acid took place rapidly after stopping the drug and the level usually achieved its pretreatment value within one week of discontinuation, regardless of the duration of therapy (Fig. 1). In a few instances, however, pretreatment values were not regained until 2 or 3 weeks after stopping the drug.

\section{(2) BLOOD UREA}

Pretreatment blood urea levels had been $45 \mathrm{mg} /$ $100 \mathrm{ml}$ or below in all the patients in whom allopurinol was stopped in the absence of side effects, but was higher in some of the patients in whom the drug was stopped because of such side effects. The mean blood urea in all patients before allopurinol was started had been $41 \mathrm{mg} / 100 \mathrm{ml}$ (SD 10), and showed no significant change during allopurinol treatment $(39 \mathrm{mg} / 100 \mathrm{ml}$; SD 12), or after allopurinol was discontinued $(37 \mathrm{mg} / 100 \mathrm{ml}$; SD 11).

Figures for creatinine clearance both before and after treatment were available in only five subjects; these showed no change after discontinuation (mean $105 \mathrm{ml} / \mathrm{min}$ before treatment, $114 \mathrm{ml} / \mathrm{min}$ after treatment was discontinued).

\section{(3) CLINICAL}

Up to the time this analysis was made there had been a recurrence of gouty arthritis in twelve patients; 21 patients have remained well and free of symptoms. Thirteen patients have restarted the drug (after a mean duration off treatment of 55 weeks). The usual reason for restarting treatment has been the recurrence of gouty arthritis, but in four patients the drug was started relatively early after it was discontinued, because either the patient or his physician preferred to do so; treatment was restarted in one patient because of uric acid crystalluria (though his 24-hour urinary uric acid before treatment had not been raised and previous microscopy of urine had shown no abnormality). Treatment was restarted in one patient who had remained symptom-free for 3 years off the drug but who was to have a prostatectomy operation; it was thought wise to avoid a risk of postoperative gout.

At the time of analysis twenty patients were still not taking allopurinol after a mean duration off treatment of 107 weeks. Fifteen of these patients had remained free of gout and five had had a mild recurrence. The course of all 33 patients is indicated in Fig. 2. 


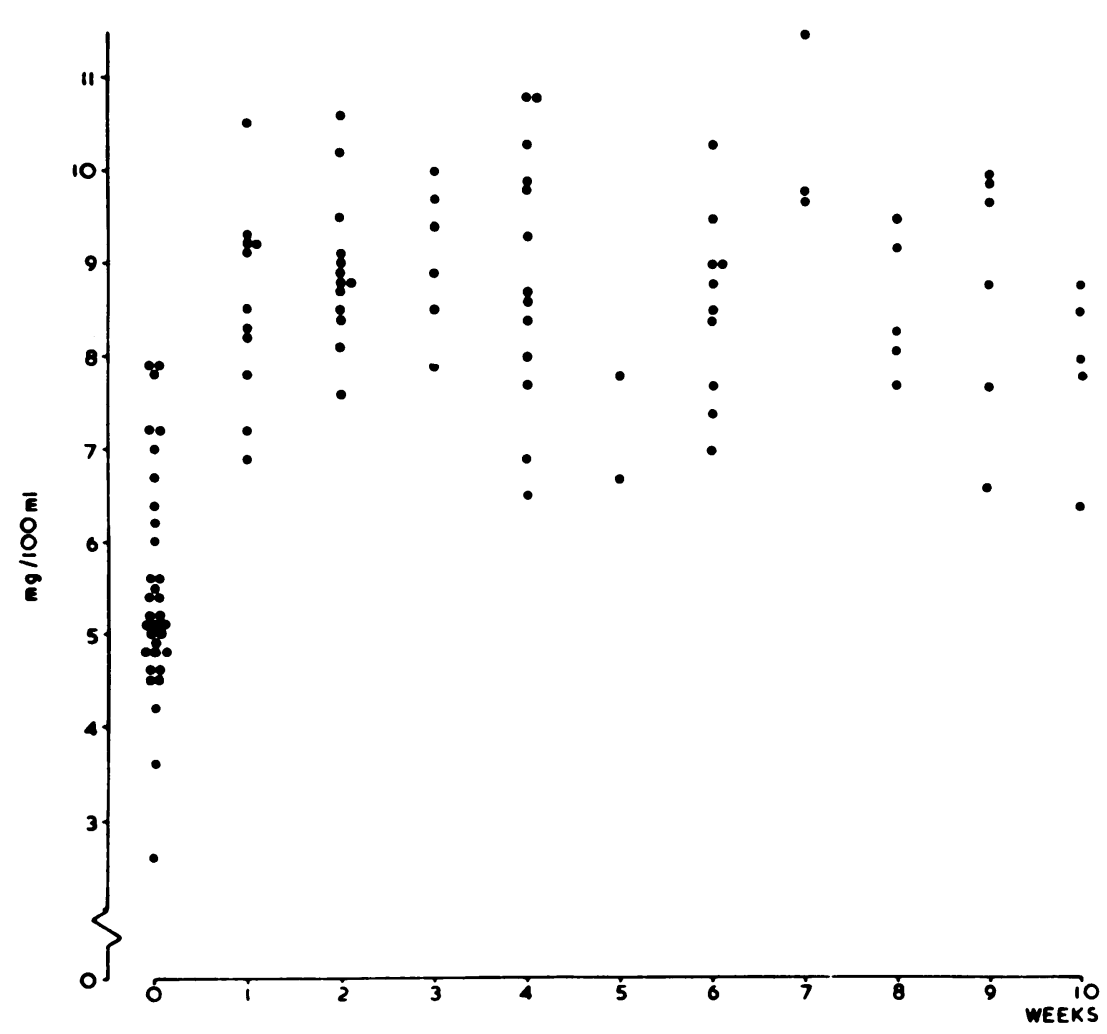

FIG. 1 Plasma uric acid levels before stopping allopurinol and for 10 weeks afterwards

A comparison of various factors between those patients suffering a recurrence of gout after stopping treatment and those who have had no recurrence as yet is indicated in the Table. There is no significant difference between the two groups with regard to the mean age at stopping allopurinol, mean duration of clinical gout, mean duration of allopurinol treatment, mean daily dose of allopurinol, and the mean initial plasma uric acid. Those patients having no recurrence of gout, however, are seen to have had a better control of plasma urate level while taking the drug (mean $5.1 \mathrm{mg} / 100 \mathrm{ml}$ ) than those who have had a recurrence of gouty arthritis (mean $6.2 \mathrm{mg} / 100 \mathrm{ml}$ ).

\section{Discussion}

Apart from the occasional occurrence of skin rashes, particularly in patients with renal failure, allopurinol appears to have remarkably few side effects. Because of its inhibitory effect on purine biosynthesis (in addition to its action as an inhibitor of xanthine oxidase), the anticipated complication of xanthine stone formation occurs with extreme rarity. It has in fact been recorded only in patients with the Lesch-Nyhan syndrome, where allopurinol fails to suppress purine biosynthesis and the urinary excretion rate of the oxypurines hypoxanthine and xanthine is high (Seegmiller, 1968; Greene, Fujimoto, and
Seegmiller, 1969), and in a patient with lymphosarcoma who received allopurinol for control of hyperuricaemia (Band, Silverberg, Henderson, Ulan, Wensel, Banerjee, and Little, 1970). Possible effects of allopurinol on iron metabolism have not been confirmed (Emmerson, 1966; Boyett, Vogler, de Paula Furtado, and Schmidt, 1968), but it appears that the drug increases the risk of bone marrow damage in

Table Status after stopping allopurinol

\begin{tabular}{|c|c|c|}
\hline & $\begin{array}{l}\text { Recurrence of } \\
\text { gout }\end{array}$ & $\begin{array}{l}\text { No recurrence } \\
\text { yet }\end{array}$ \\
\hline $\begin{array}{l}\text { Mean age at stopping } \\
\text { allopurinol }\end{array}$ & $58 \cdot 2$ yrs & $57 \cdot 3$ yrs \\
\hline $\begin{array}{l}\text { Mean duration of } \\
\text { clinical gout }\end{array}$ & $16 \mathrm{yrs}$ & $15 \mathrm{yrs}$ \\
\hline $\begin{array}{l}\text { Mean duration allo- } \\
\text { purinol treatment }\end{array}$ & $\begin{array}{l}82 \text { wks } \\
( \pm \text { SD 54) }\end{array}$ & $\begin{array}{l}99 \text { wks } \\
( \pm \text { SD 59) }\end{array}$ \\
\hline $\begin{array}{l}\text { Mean daily dose } \\
\text { allopurinol }\end{array}$ & $388 \mathrm{mg}$ & $368 \mathrm{mg}$ \\
\hline Mean initial PUA & $8.6 \mathrm{mg} / 100 \mathrm{ml}$ & $8.4 \mathrm{mg} / 100 \mathrm{ml}$ \\
\hline $\begin{array}{l}\text { Mean PUA during } \\
\text { treatment }\end{array}$ & $\begin{array}{l}6.2 \mathrm{mg} / 100 \mathrm{ml} \\
( \pm \mathrm{SD} 1.4)\end{array}$ & $\begin{array}{l}5.1 \mathrm{mg} / 100 \mathrm{ml} \\
( \pm \mathrm{SD} \mathrm{0.9)}\end{array}$ \\
\hline
\end{tabular}




\section{DURATION OFF ALLOPURINOL}



FIG. 2 Clinical course of all 33 patients after stopping allopurinol

patients with neoplastic diseases who are receiving chemotherapy, particularly cyclophosphamide, probably because of an interaction between allopurinol and cytotoxic drugs (Boston Collaborative Drug Surveillance Program, 1974). Crystals of hypoxanthine, xanthine, and oxipurinol have been found in skeletal muscle biopsies from patients with gout who were being treated with allopurinol (Watts, Scott, Chalmers, Bitensky, and Chayen, 1971), but this finding does not appear to have any clinical significance. A theoretical possibility has been the incorporation of allopurinol ribonucleotide into nucleic acids, but experimental support for this is lacking (Nelson, Buggé, Krasny, and Elion, 1973; Nelson and Elion, 1974).

The present study was begun at a time when the last two possibilities were perhaps causing more anxiety than is the case at present; it was considered justifiable to discontinue allopurinol in a group of gouty patients without over-production of uric acid and without renal failure, and to observe their progress. Plasma levels of uric acid rose rapidly to pretreatment values in all subjects, but gouty arthritis has recurred in only a minority of them and attacks seem to have been mild. Presumably the total body content of urate is depleted during the period of treatment, and time is required for re-accumulation of urate, its precipitation in solid form, and the subsequent development of gouty arthritis. In this context it is of interest that there was no significant difference with regard to duration of allopurinol treatment between those subjects who have not yet had a recurrence of gouty arthritis compared with those who have; but control of plasma urate levels while taking the drug had been better in the former than in the latter.

Assessment of renal function was not entirely satisfactory because some of the patients were seen for the first time after treatment was started, and in most subjects levels of creatinine clearance before, during, and after treatment were not available for comparison. The few which were, however, showed no change and levels of blood urea in all subjects remained constant, with no indication of any overall change either during treatment or after its cessation.

Evidently allopurinol can be discontinued in patients with uncomplicated gouty arthritis for relatively long periods without recurrence of their symptoms. It is currently accepted practice, however, that once a decision has been taken to start allopurinol (or uricosuric) treatment this should be continued indefinitely, and the results of the present study do not give any grounds for changing this concept. 


\section{Summary}

A few years ago the possibility was raised that allopurinol ribonucleotide might be incorporated into genetic material. Another potential hazard was suggested by the finding of crystals of allopurinol and oxipurinol in muscle biopsy specimens from patients taking allopurinol. It subsequently appears that the first eventuality does not in fact occur and that the second is of no clinical significance. At the time, however, it was thought to be reasonable to determine the effect of discontinuing allopurinol therapy in gouty patients who were not over-producers of uric acid and whose renal function was not impaired.

Medication was discontinued in 33 patients who had been taking allopurinol for a mean period of nearly 2 years (93 wks, range 19-236 wks). Plasma uric acid always rose rapidly and reached pretreatment levels in one or two weeks. After a mean period off treatment of 86 weeks (range 14 wks4 yrs), twenty of the 33 patients remain off the drug and are mostly free of symptoms, while therapy has been restarted in thirteen patients, the most usual individual reason being recurrence of acute gout. There has been no overall change in renal function (blood urea). Thus, though a rapid rise in uric acid is invariable, clinical symptoms have so far occurred in only a minority of patients.

We are indebted to Mrs. Hannelore Yablonsky who carried out uric acid estimations, and to Dr. Anne Nicholls and Dr. Michael Snaith who collaborated in the study. The work was supported by the Arthritis and Rheumatism Council for Research.

\section{DISCUSSION}

PROF. E. G. L. BYWATERS (Taplow) It would be very interesting to know if there was any correlation within the recurrence group with age of onset. I gather that comparing the two groups you found that the age of onset was, on average, the same, but as uric acid is accumulated in these patients, I suppose at the same rate each year, presumably the earlier the onset of gout the greater the rate and amount of urate retained.

DR. W. Y. LOEBL We did in fact look at this point and there was no correlation.

DR. H. C. BUR R Y (Guy's Hospital) I wonder what tests of renal function you carried out. It did seem that some of the blood ureas were above the normal range from the statistics you showed. I wondered whether there was any correlation between GFR and the recurrence of gout subsequently.

DR. W. Y. LOEBL There was no correlation between blood urea levels and the recurrence of gout. Creatinine clearance was performed in only a minority of patients and again showed no correlation with recurrence.

DR. J. T. ScotT If I may just amplify that reply? The few patients with high blood ureas were stopped because of rashes. Those who were stopped arbitrarily all had renal function which was normal as judged by blood urea or they would not have had the drug discontinued. Most of the patients have had 24-hour creatinine clearance estimation at some time but some of them had been started on treatment elsewhere so we did not have these pretreatment figures. I entirely accept that it would be much better to have creatinine clearance estimations as well as the more crude blood urea estimations.

We do not want to give a false impression of our views about allopurinol. Ever since the drug was introduced its path has been strewn with reports of toxicity. First of all there was the iron storage and haemochromatosis story, and then there was the xanthine stone fear, but this has occurred only in exceptional cases of HGPRT deficiency or in lymphosarcoma, but not in the ordinary treatment of gout. Then there was the fear of incorporation into nucleic acids, but this apparently does not take place. Then there were the crystals which were found in muscle biopsies, but the significance of these is very uncertain to say the least, as follow-up in these patients has not shown any clinical effect. So despite all this, allopurinol does seem to remain a very safe drug and I do not think we want to create any other impression. We did stop the drug for the reasons that were given and the data were thought to be of some interest.

\section{References}

Band, P. R., Silverberg, D. S., Henderson, J. F., Ulan, R. A., Wensel, R. H., Banerjee, T. K., and Little, A. S. (1970) New Engl. J. Med., 283, 354 (Xanthine nephropathy in a patient with lymphosarcoma treated with allopurinol)

Boston Collaborative Drug Surveillance Program (1974) J. Amer. med. Ass., 227, 1036 (Allopurinol and cytotoxic drugs)

Boyett, J. D., Vogler, W. R., de Paula Furtado, V., and Schmidt, F. H. (1968) Blood, 32, 460 (Allopurinol and iron metabolism in man)

Emmerson, B. T. (1966) Ann. rheum. Dis., 25, 700 (Effects of allopurinol on iron metabolism in man)

Greene, M. J., Fujimoto, W. Y., ANd Seegmiller, J. E. (1969) New Engl. J. Med., 280, 426 (Urinary xanthine stones-a rare complication of allopurinol therapy)

Nelson, D. J., Buggé, C. J. L., Krasny, H. C., AND Elion, G. B. (1973) Biochem. Pharmacol., 22, 2003 (Formation of nucleotides of $\left[6-{ }^{14} \mathrm{C}\right]$ allopurinol and $\left[6-{ }^{14} \mathrm{C}\right]$ oxipurinol in rat tissues and effects on uridine nucleotide pools)

—, AND Elion, G. B. (1974) Personal communication

Scott, J. T., Hall, A. P., AND Grahame, R. (1966) Brit. med. J., 2, 321 (Allopurinol in treatment of gout)

Seegmiller, J. E. (1968) Fed. Proc., 27, 1097 (Seminars on the Lesch-Nyhan syndrome: management and treatment, discussion)

Watts, R. W. E., Scott, J. T., Chalmers, R. A., Bitensky, L., And Chayen, J. (1971) Quart. J. Med., 40, 1 (Microscopic studies on skeletal muscle in gout patients treated with allopurinol) 